\title{
DILUTION IN LASER CLADDING WITH Ni-BASED POWDERS
}

\author{
D. C. Cuculea, G. L. Ardelean, E. M. Stanciu, \\ I. C. Roata, A. Pascu* \\ Transilvania University of Brasov, Faculty of Materials Science and Engineering, \\ 1 Universitatii St., 500068, Brasov, Romania \\ *Corresponding author's e-mail address: alexandru.pascu@unitbv.ro
}

\begin{abstract}
This study addresses to the laser cladding of nickel-based powders on stainless steel substrate. A TRUMPH pulsed laser and a coaxial cladding module are used to fabricate single tracks on AISI 304 substrate. The influence of the laser power on the geometric characteristics and microstructure of the cladded layer is investigated using optical and scanning electron microscopy and energy dispersive X-ray spectroscopy. Dilution is determined using the melt depth of the cladded tracks and validated using the local chemical microanalysis. The results showed that laser power have a major influence on the dilution and melted area of the laser cladded tracks.
\end{abstract}

KEYWORDS: laser cladding, metallic powder, dilution, stainless steel AISI 304, geometric characteristics.

\section{INTRODUCTION}

Nowadays the laser cladding became a conventional process for creating new surfaces or recondition the worn parts. The laser cladding is a technological technique in which the laser radiation is utilised as thermal source and a metallic powder is melted and forms a layer / cladding [1]-[3]. The process is an interdisciplinary technology which uses the laser radiation, CAD/CAM design, robotic arms, sensors and a metallic powder for fabricate the new layers.

The deposited material can be cladded with different methods: i) one-step process, ii) two-step process. Between these ways of deposition, the onestep process uses an off-axis or coaxial cladding head being the most effective method for obtaining high quality layers. The process is characterised by numerous advantages such as: precision, metallurgical bonding with the substrate, low dilution and availability of a large range of materials that can be deposited using this technology [4]-[6].

The process is highly dependent of the feedstock powder handling, respectively the geometry of cladding head, nozzle geometry and inclination that should be considered for obtaining a constant aspect ratio of the deposited track [7]. Besides all the advantages, the process is highly influenced by the process parameters that can alter the final results. In a complete study $\mathrm{Yu}$ at al. [5] investigate the effect of process parameters on the laser clad track geometry and concluded that scanning speed has a clear influence on the height of the track and power on the melt depth and HAZ. In a similar study Nikhil [6] reveals the influence of the process parameters on distortion and melt pool behaviour for cladding with Stellite 6 powder on SS316. The substrate is subjected to higher distortion rate when using high laser power and low scanning speed. Moreover, the melt pool temperature increases at higher Linear Heat Input (LHI). The high temperature and cooling rate have a negative impact on the cracking susceptibility which is an ongoing research concerning the laser cladding with superalloys.

Zhang et al. [8] study the evolution behaviour and cracking mechanism to suppress liquation cracking of K447A Ni-based superalloy. He determined the formation mechanism of liquation cracking and conclude that a shock peening pre-treatment of the base material can reduce the cracking susceptibility. The laser cladding is dependent of the process parameters optimisation that is the best method to enhance the quality and reduce the dilution of produced layers [9].

Tanigawa et al. [10] obtain a low dilution on 304 stainless stell by controlling the laser beam profile. He used a flat top beam profile to suppress droplet generation and was able to produce low dilution cladded layers. Zhai et al. [11] used electromagnetic compound field to reduce the dilution by mitigating the convective movement of the melted bath.

The dilution is a very important factor for controlling the diffusion of the substrate elements into the coating. Even though a minimum level of mixture is necessary for a good adherence to the base material, an excessive dilution may modify all the coating properties in a negative way. In the most common measurement method, the dilution is equal to: 


$$
d=\frac{A_{m}}{A_{c}+A_{m}}
$$

where $A_{m}$ is the cross-sectional area of the melted area of the substrate and $A_{c}$ is the coating area (Figure 1, schematic 9). The values of dilution or the mixture between the substrate and the coating must be as small as possible; the literature reports 5 to $10 \%$ being the optimal percentage of dilution related to laser cladding with powders.

The objective of this study is to determine the influence of the laser power on the dilution, geometrical appearance and microstructure of the NiCrBSiC coating. The geometrical characteristics influence the dilution between the coating and substrate and also the microstructure of the cladded layers.

The novelty of this study rises from the use of pulsed laser that is uncommon for the cladding deposition. Supplementary parameters such us: pulse duration and repetition rate are used to set up the laser power density compared with the continuous one where only the power should be defined. Usually, the laser pulses increase the melt depth and dilution.

\section{MATERIALS AND METHODS}

\subsection{Materials}

The filler material used in this study is a Ni-based hard alloy powder (Oerlikon Metco 12C) and 60x60x8 mm stainless steel plate AISI 304 was used as substrate. This powder has a spheroidal morphology for freelyflowing material feed during laser cladding process. The chemical composition of materials is summarised in Table 1 and Table 2.

Table 1. Chemical composition of the Metco 12C metallic powder

\begin{tabular}{ccccc}
\hline $\mathrm{C}[\%]$ & $\mathrm{Si}[\%]$ & $\mathrm{Fe}[\%]$ & $\mathrm{B}[\%]$ & $\mathrm{Cr}[\%]$ \\
\hline 0.25 & 3.5 & 2.5 & 1.7 & 7.5 \\
\hline
\end{tabular}

Table 2. Chemical composition of AISI 304 (1.4301)

\begin{tabular}{ccccccc}
\hline $\mathrm{C}$ & $\mathrm{Mn}$ & $\mathrm{Si}$ & $\mathrm{P}$ & $\mathrm{S}$ & $\mathrm{Cr}$ & $\mathrm{Ni}$ \\
{$[\%]$} & {$[\%]$} & {$[\%]$} & {$[\%]$} & {$[\%]$} & {$[\%]$} & {$[\%]$} \\
\hline 0.07 & 2.00 & 1.00 & 0.045 & 0.030 & 19.5 & 10.5 \\
\hline
\end{tabular}

Table 3. The process parameters and geometric characteristics

\begin{tabular}{|l|c|c|c|c|c|c|c|c|}
\hline \multicolumn{1}{|c|}{$\begin{array}{c}\text { Parameters / } \\
\text { tracks }\end{array}$} & $\mathbf{1}$ & $\mathbf{2}$ & $\mathbf{3}$ & $\mathbf{4}$ & $\mathbf{5}$ & $\mathbf{6}$ & $\mathbf{7}$ & $\mathbf{8}$ \\
\hline Laser power [W] & 900 & 1000 & 1100 & 1200 & 1300 & 1400 & 1500 & 1600 \\
\hline Speed [cm/min] & 30 & 30 & 30 & 30 & 30 & 30 & 30 & 30 \\
\hline $\begin{array}{l}\text { Powder quantity } \\
\text { [g/min] }\end{array}$ & 5 & 5 & 5 & 5 & 5 & 5 & 5 & 5 \\
\hline Width [mm] & 1.42 & 1.30 & 1.45 & 1.54 & 1.52 & 1.78 & 1.62 & 1.49 \\
\hline $\begin{array}{l}\text { Melt depth area } \\
{\left[\mathrm{mm}^{2}\right]}\end{array}$ & 0.05 & 0.12 & 0.11 & 0.14 & 0.20 & 0.22 & 0.28 & 0.36 \\
\hline Clad area [mm²] & 0.19 & 0.26 & 0.34 & 0.39 & 0.43 & 0.52 & 0.54 & 0.53 \\
\hline Dilution (d) [\%] & 21.97 & 31.38 & 25.93 & 26.62 & 31.84 & 29.96 & 34.61 & 40.58 \\
\hline
\end{tabular}

\subsection{Experimental Frame}

The cladding process was performed using a pulsed Nd:YAG laser "Trumpf TruPulse 556" with a peak pulse power of $10 \mathrm{~kW}$ and a PRECITEC YC 50 coaxial cladding head at $200 \mathrm{~mm}$ focal length. The powder was supplied into the cladding unit by a AT-1200HPHV Termach feeding system using Argon as transport and shielding gas. The powder was fed into the cladding chamber through the nozzle four sockets and released uniformly around the laser beam. The experimental tests were carried out by increasing the laser power by $100 \mathrm{~W}$ and maintaining the cladding speed and powder feed rate unchanged, as shown in the table 3 .

\subsection{Methods}

The macro images of the samples were captured using the LEICA EZ4 stereo microscope. The microstructures and dilution of the cladded tracks were analysed and determined by optical microscopy using a LEICA DML inverted microscope and by scanning electron microscopy (SEM: Quanta FEG 250, FEI, The Netherlands) using back scattered electron detector (BSD) and elemental analysis was performed by energy dispersive X-ray spectroscopy (EDS with Apolo SSD: detector, EDAX Inc. US). 


\section{RESULTS AND DISCUSSION}

The literature [12] - [17] and several preliminary tests have been used to determine the parameters window for this study. Eight single tracks have been produced by laser cladding using the parameters from table 3 . The laser spot diameter was $2.2 \mathrm{~mm}$ and the pulse width $1.8 \mathrm{~ms}$ at a repetition rate of $80 \mathrm{~Hz}$. Three identical samples were produced to ashore a good process repeatability. The tests showed that laser power is the most influencing factor for dilution and dimensional characteristics of the coating. Figure 2 show the cross-section area of the individual cladding tracks/lines. The influence of the laser power on the dimensional characteristics of coatings is highlighted by the samples 1 to 8 (fig. 1) being clearly visible that all the geometrical characteristics increases almost linear with the laser power.
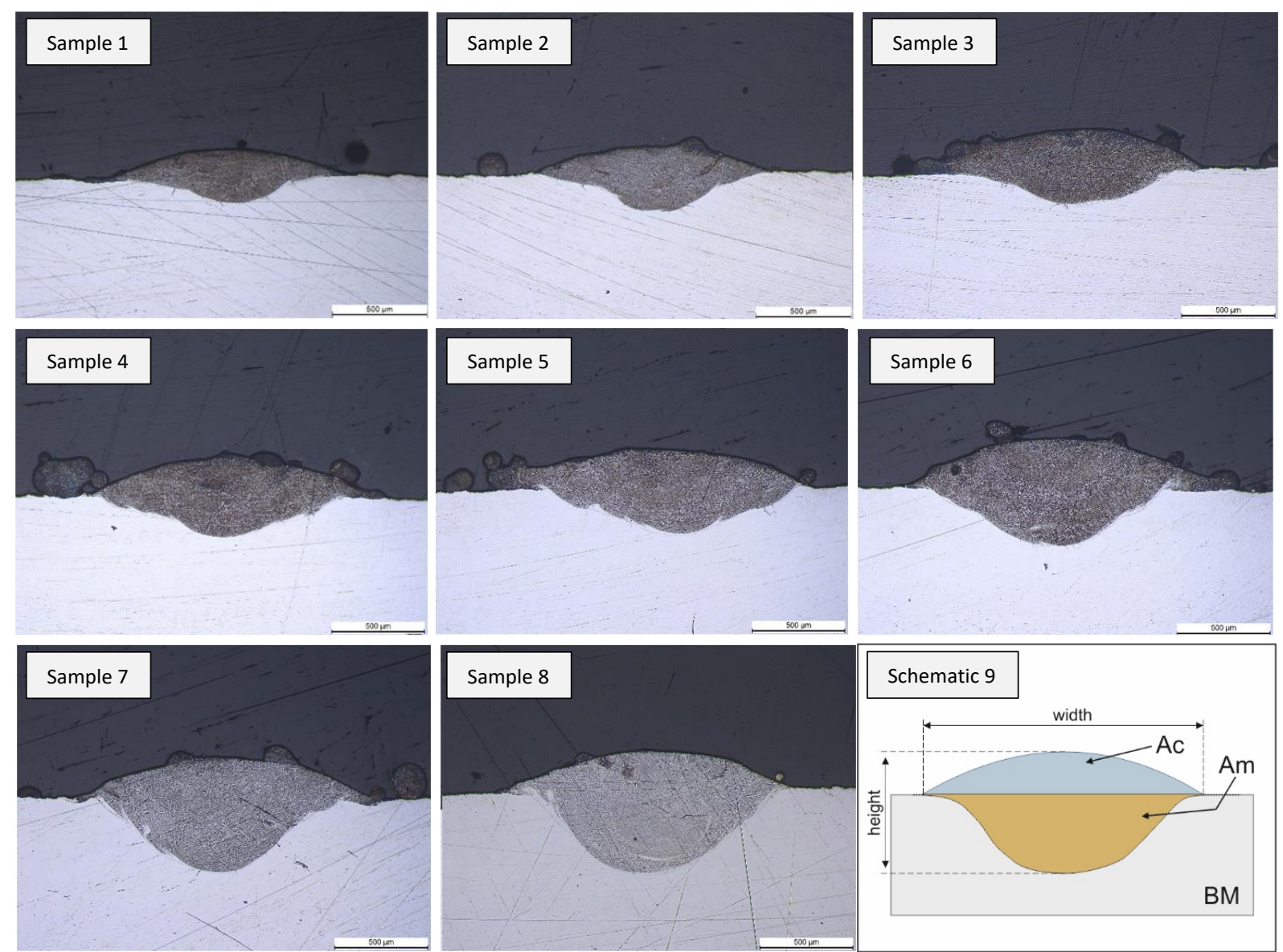

Fig. 1. Cross-section area of individuals cladding lines: sample no. 1 to sample no. 8 and schematic representation of the track main geometric characteristics

The graphical representation from figure $2 \mathrm{a}$ shows that laser power has a direct influence on the cladded area which increase at higher laser energy. The cladded layer area is influenced by the laser power as follows: i) at higher power, a higher quantity of powder is melted before reaching the melt pool and ii) the increased power creates a larger melt pool that melts more powder. Therefore, at higher laser power a larger quantity of powder is melted and cladded on the substrate. Even so, the graph from fig. 2a show that coating area has a saturation point and indicates a tendency to stagnate at values higher than $1400 \mathrm{~W}$, mainly due to the constant powder feeding.

The figure $2 b$ show the laser power influence on the dilution. The melt depth area and therefore the dilution percent is increasing at higher laser power. The laser power has a direct influence on the melting depth of the substrate and at a constant cladding speed a larger melt pool will be created. A higher melt depth will promote a high dilution, respectively the mixing of substrate with the cladded tracks.

Dilution is the unwanted effect of elements diffusion from the substrate, mainly iron, into the cladded layer as can be observed from EDS analyses. Iron diffusion from the base material can mitigate the hardens and corrosion resistance of the layers cladded with high alloyed materials.

All the obtained samples have a microstructure characterised by coarse, columnar dendritic structure at the boundary with the substrate and by a fine, uniform and even distributed dendrite structure at the upper part of the coating. The primary structure of the $\mathrm{NiCrBSi}$ cladded track is $\mathrm{Y}$-Ni solid solution. 


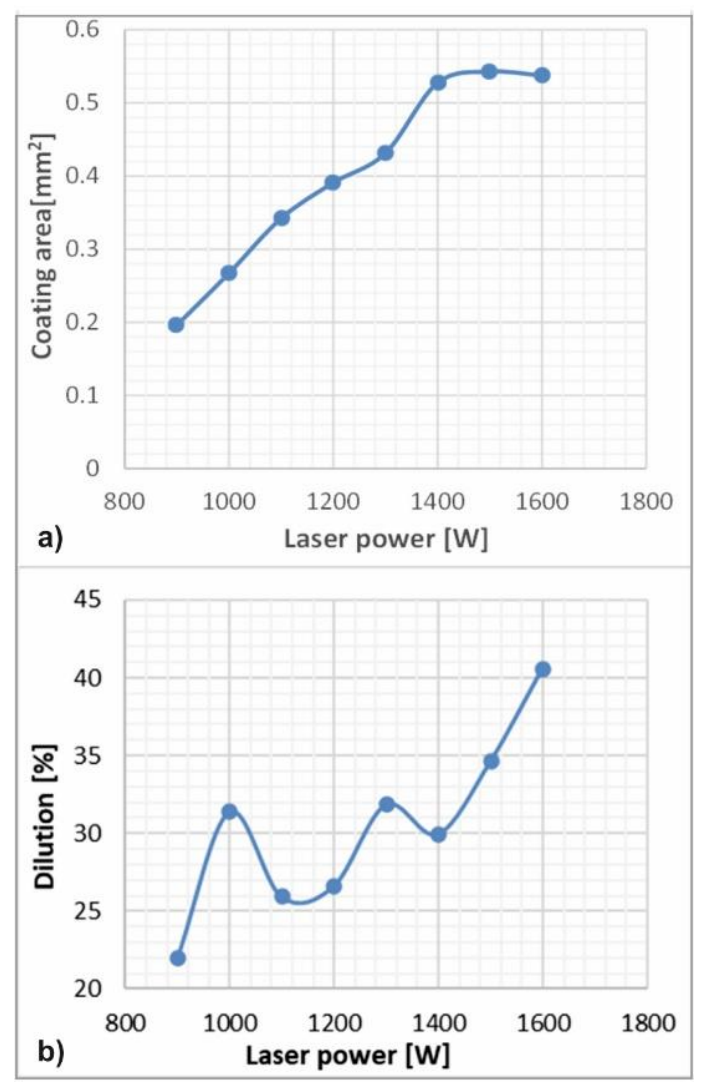

Fig. 2. Representation of the laser power influence on the melted zone area dilution (a) and dilution (b)
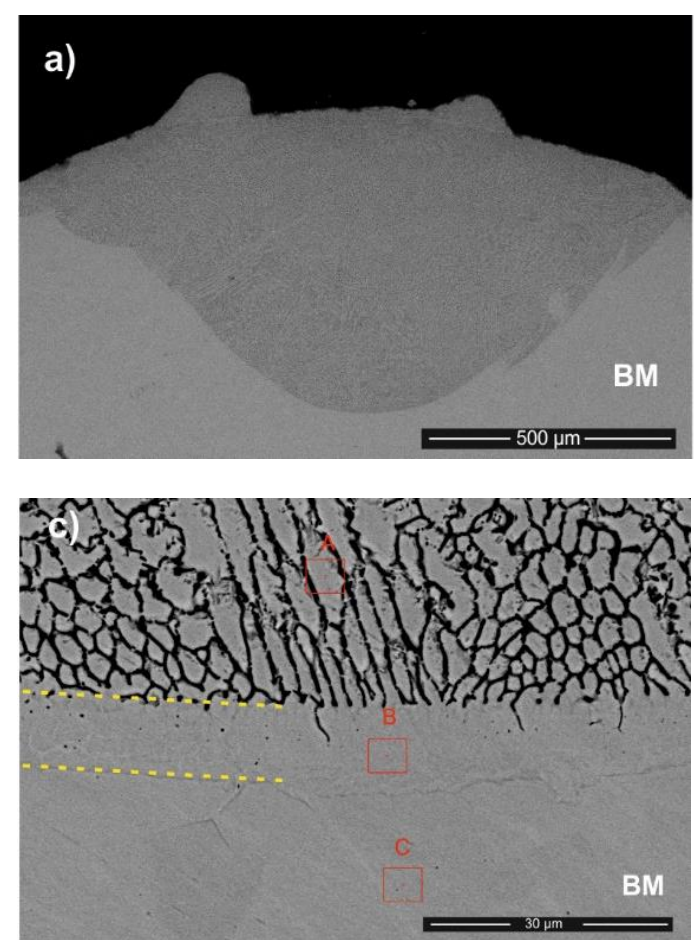
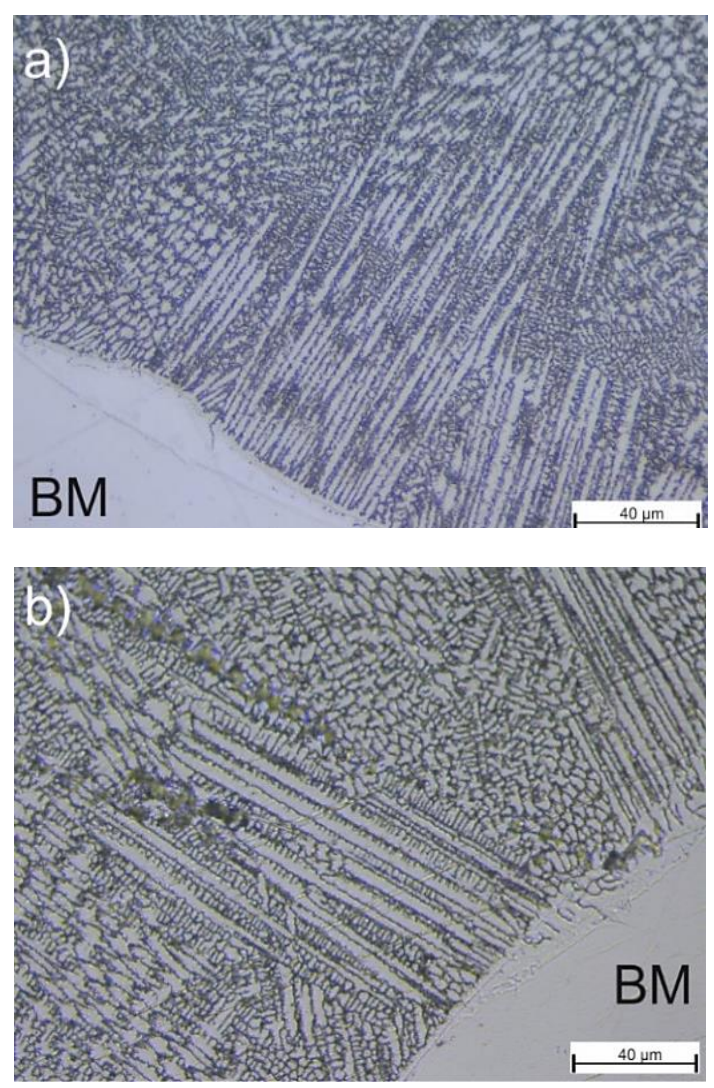

Fig. 3. Columnar dendrite at the boundary of the cladding and substrate: a) sample 6; b) sample 7

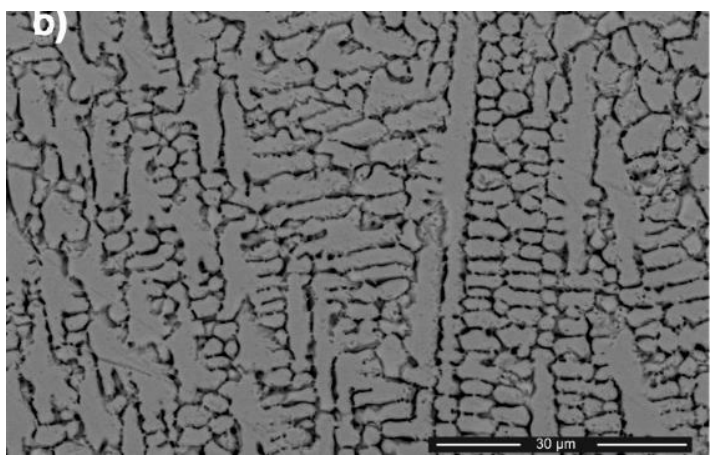

Fig. 4. SEM analyses of the sample 7: a) appearance of the cladding layer; b) microstructure near the surface of the cladded track, c) detail of the boundary zone and location of the EDS analyses, d) EDS analyses according with microzones from figure $4 c$ ) 
Figure $3 \mathrm{a}$ and $\mathrm{b}$ show the columnar growth of branch trees dendrite located at the interface with the base material. The directions of the dendrite growth correspond with the solidification path that follows the direction of the laser interaction.

Near this large dendrite can be identified (fig. 4c) a well-defined non-interference line (planar growth) between the clad and the base material. This noninterference line of $10 \mu \mathrm{m}$ is a well-known feature of metallurgical bonding characteristic of the laser cladding process [18]. This line occurs due the fast cooling of the melted pool. Figure 4d. presents the EDS analyses at the interface between the cladded track and substrate according with the microzones from figure 4c. The $\mathrm{C}$ and $\mathrm{O}$ contents should not be considered as the high $\mathrm{C}$ content being a SEM contamination (wellknown issue in EDS analyses) and $\mathrm{O}$ is resulted as various surface oxides. Even so, the EDS analyses reveals a high iron quantity in the cladded track. The A area presents a higher content of iron diffused from the substrate as can be compared with the chemical composition of the stock powder that has only $2.5 \%$ iron.

\section{CONCLUSIONS}

The study reveals the influence of the laser power on the dilution and the dimensional characteristics of the cladded tracks.

The Ni-based Oerlikon Metco 12C powder was cladded on stainless steel AISI 304 using pulsed laser radiation. The dimensional characteristics of the cladded layer depend primary of the technological parameters and by the filler material that is utilised. The dilution, the melted zone area and the coating area are directly influenced by the laser radiation power.

The dilution was doubled, namely from $20.9 \%$ to $40.5 \%$ when the laser power was increased from 900 $\mathrm{W}$ to $1600 \mathrm{~W}$ which indicate the dependence between the power and melt depth / dilution. A high-quality coating is obtained by precise controlling the dilution that is influenced by the laser energy used during the process. The total laser energy can be fine-tuned controlling the power, spot diameter and cladding speed.

\section{REFERENCES}

[1] Pascu A., Stanciu E. M., Savastru D., Geanta V., Croitoru C., Optical and microstructure characterisation of ceramic Hydroxyapatite coating fabricated by laser cladding, Journal of Optoelectronics and Advanced Materials, vol.19 (1-2), 2017, pp. 6672.

[2] Zhang H., Zou Y., Zou Z., Wu D., Microstructure and properties of $\mathrm{Fe}$-based composite coating by laser cladding $\mathrm{Fe}-\mathrm{Ti}$ $\mathrm{V}-\mathrm{Cr}-\mathrm{C}-\mathrm{CeO} 2$ powder, Optics and Laser Technology, vol.65, 2015, pp. $119-125$.
[3] Stanciu E. M., Pascu A., Tierean M. H., Voiculescu I., Roată I. C., Croitoru C., Hulka I., Dual coating laser cladding of NiCrBSi and Inconel 718, Materials and manufacturing processes, vol. 31, 2016, pp.1556-1564.

[4] Pascu A., Mirza Rosca J., Stanciu E. M., Laser cladding: from experimental research to industrial applications. Materials Today: Proceedings, vol. 19, 2019, pp.1059-1065.

[5] Yu Z., Chuang G., Liaoyuan C., Jiayu S., Tianbiao Yu, Effect of process parameters on the cladding track geometry fabricated by laser cladding, Optik, vol. 223, December 2020, 165447

[6] Nikhil T., Chaitanya G., Aayush C., Gupta T. V. K., Influence of laser cladding parameters on distortion, thermal history and melt pool behaviour in multi-layer deposition of stellite 6: Insitu measurement, Journal of Alloys and Compounds, vol. 860, 2021, 157894.

[7] Ambrish S., Sajan K., Manas D., A comprehensive review of the methods and mechanisms for powder feedstock handling in directed energy deposition, Additive Manufacturing, vol. 35, 2020, 101388.

[8] Zhenlin Z., Yue Z., Jiguo S., Aiping W., Yutaka S. S., Shun T., Kota K., Hiroshige I., Huaipeng G., Xin T., Evolution behavior of liquid film in the heat-affected zone of laser cladding nonweldable nickel-based superalloy, Journal of Alloys and Compounds, vol. 863, 2021, 158463.

[9] Daichi T., Yoshinori F., Nobuyuki A., Masahiro T., Yoshihiko H., Hiroyuki Y., Yoshihiro T., Mikio Y., Suppression of dilution in $\mathrm{Ni}$-Cr-Si-B alloy cladding layer by controlling diode laser beam profile, Optics and Laser Technology, vol. 99, 2018, pp. 326-332.

[10] Lulu Z., Chunyan B., Junwei Z., Xiaoyan Y., Characteristics of dilution and microstructure in laser cladding $\mathrm{Ni}$-Cr-B-Si coating assisted by electromagnetic compound field, Materials Letters, vol. 243, 2019, pp.195-198.

[11] Lucia L., Marco S., Rachele B., Andrea G., Stefania B., Francesco F., Silvano R., On the influence of laser cladding parameters and number of deposited layers on as-built and machined AISI H13 tool steel multilayered claddings, CIRP Journal of Manufacturing Science and Technology, vol. 35, 2021, pp. 361370 .

[12] Sha W., Zenghua L., Xiaofei H., Yufeng W., Yu G., Process parameter optimization and EBSD analysis of Ni60A-25\% WC laser cladding, International Journal of Refractory Metals and Hard Materials, vol. 101, 2021, 105675.

[13] Devojno O.G., Feldshtein E., Kardapolava M.A., Lutsko N.I., On the formation features, microstructure and microhardness of single laser tracks formed by laser cladding of a NiCrBSi selffluxing alloy, Optics and Lasers in Engineering, vol. 106, 2018, pp. 32-38

[14] Shang S., Wellburn Dan, Sun Y.Z., Wang S.Y., Cheng J., Liang J., Liu C.S., Laser beam profile modulation for microstructure control in laser cladding of an NiCrBSi alloy, Surface and Coatings Technology, vol. 248, 2014, pp. 46-53

[15] Amirreza F., Farshid M. G., Jamshid S., Effects of pulse duration and overlapping factor on melting ratio in preplaced pulsed Nd:YAG laser cladding, Optics and Lasers in Engineering, vol. 51, Issue 1, 2013, pp. 69-76

[16] Zhenlin Z., Yue Z., Yang C., Zhen S., Jiguo S., Aiping W., Yutaka S.S., Huaipeng G., Xin T., The role of the pulsed-wave laser characteristics on restraining hot cracking in laser cladding non-weldable nickel-based superalloy, Materials \& Design, vol. 198, 15 January 2021, 109346

[17] Hyoung-Keun Lee, Effects of the cladding parameters on the deposition efficiency in pulsed Nd:YAG laser cladding, Journal of Materials Processing Technology, vol. 202, Issues 1-3, 2008, pp. 321-32.

[18] Ting Y., Jie C., Yimeng W., Qilin D., High temperature phase stability and wear behavior of laser clad Ta reinforced NiCrBSi coating, Applied Surface Science, vol. 547, 2021, 149171. 